American Journal of Pharmaceutical Education 2019; 83 (4) Article 7378.

\title{
COMMENTARY
}

\section{Revisiting Faculty Citizenship}

Dana P. Hammer, PhD, MS, ${ }^{a}$ Leigh Ann Bynum, PhD, MS, ${ }^{b}$ Jean Carter, PharmD, PhD, MS, ${ }^{\mathrm{c}}$

Nicholas E. Hagemeier, PharmD, PhD, ${ }^{\mathrm{d}}$ Daniel R. Kennedy, PhD, MS, ${ }^{\mathrm{e}, \mathrm{f}}$ Parto Khansari, PhD, MS, ${ }^{\mathrm{g}}$ Pamela Stamm, PharmD, ${ }^{\text {h }}$ Brian Crabtree, PharmD ${ }^{\mathrm{i}}$

${ }^{a}$ University of Colorado Skaggs School of Pharmacy and Pharmaceutical Sciences, Aurora, Colorado

${ }^{\mathrm{b}}$ Belmont University College of Pharmacy, Nashville, Tennessee

${ }^{\mathrm{c}}$ University of Montana College of Health Professions and Biomedical Sciences, Missoula, Montana

${ }^{\mathrm{d}}$ East Tennessee State University Bill Gatton College of Pharmacy, Johnson City, Tennessee

${ }^{\mathrm{e}}$ Western New England College of Pharmacy and Health Sciences, Springfield, Massachusetts

${ }^{\mathrm{f}}$ Editorial Board Member, American Journal of Pharmaceutical Education, Arlington, Virginia

${ }^{g}$ Stony Brook School of Pharmacy and Pharmaceutical Sciences, Stony Brook, New York

${ }^{\mathrm{h}}$ Auburn University Harrison School of Pharmacy, Auburn, Alabama

${ }^{i}$ Mercer University College of Pharmacy, Atlanta, Georgia

Submitted September 14, 2018; accepted January 28, 2019; published May 2019.

This commentary describes the significance of faculty citizenship in the broader context of institutional culture and defines faculty citizenship for use across all aspects of faculty roles in the Academy. The definition includes two key components (engagement and collegiality) that can be used to measure citizenship behaviors. Continued discussion and study of faculty citizenship will further the Academy's understanding and use of the concept.

Keywords: faculty service, faculty collegiality, faculty engagement, organizational citizenship, academic citizenship

\section{INTRODUCTION}

Faculty citizenship and institutional culture are important to the health and success of any college or school of pharmacy, and greater attention has been paid to these topics in the Academy in recent years. Pharmacy education scholars have published results of studies in these areas, and the American Association of Colleges of Pharmacy (AACP) programming has included sessions that address these topics directly or indirectly. ${ }^{1-4}$ Standard 9 (Organizational Culture) in the Accreditation Council for Pharmacy Education's Standards 2016 for the Doctor of Pharmacy Degree programs lists three key elements that directly relate to faculty behavior and the culture of the institution: leadership and professionalism, behaviors, and culture of collaboration. ${ }^{5}$ Prior to the implementation of Standards 2016, the 2014-15 AACP Council of Faculties Faculty Affairs Committee was charged with examining the concept of faculty citizenship. ${ }^{6}$ This commentary describes the results of this

Corresponding Author: Dana Hammer, University of Colorado Skaggs School of Pharmacy and Pharmaceutical Sciences, Office of Experiential Education, 12850 E. Montview Blvd., M/S C238, Rm. V20-1116, Aurora, CO 80045. Tel: 206-854-6400. E-mail:

dana.hammer@ucdenver.edu examination from the perspective of recent literature, and provides a definition and recommendations for use of faculty citizenship in the Academy.

\section{Organizational Citizenship Behaviors and their Re- lationship to Pharmacy Faculty}

Within any organization, there is recognition that the behavior of individual employees will impact others and an expectation that the employees will behave in a manner that will benefit the organization. The study of these interactions has been termed organizational citizenship behaviors (OCB). The OCB have been described as discretionary, extra-role behaviors that contribute to organizational effectiveness, yet are not formally required by the organization. ${ }^{7}$ Since Bateman and Organ first discussed OCB in the work environment in $1983,{ }^{8}$ it has received much attention from organizational researchers. Of the many different conceptualizations of OCB, the 1988 model introduced by Organ has received the most empirical attention. ${ }^{9}$ Organ's model is composed of five unique factors: altruism, conscientiousness, sportsmanship, courtesy, and civic virtue. ${ }^{10} \mathrm{~A}$ key component of Organ's conceptualization of OCB is that over time, these behaviors will enhance overall organizational performance. 


\section{American Journal of Pharmaceutical Education 2019; 83 (4) Article 7378.}

While management literature provides a wellresearched definition of OCB in traditional workplace settings, the extent to which this literature applies to academic institutions generally, and to pharmacy schools and colleges specifically, is relatively limited. Lawrence and colleagues studied the relationship of organizational commitment to faculty citizenship in terms of institutional service (focusing on the civic virtue component of Organ's model). They found that faculty members' levels of institutional service were not related to their levels of organizational commitment, but were inversely affected by levels of teaching and research. ${ }^{11}$ In 2016, Desselle and Semsick published results from a Delphi study that looked at organizational citizenship behaviors of pharmacy faculty. ${ }^{1}$ Twenty-six identified behaviors corresponded to Organ's five dimensions of organizational citizenship. They suggest that these behaviors can be modeled by faculty and should lead to a positive culture within their institutions.

Traditional faculty positions are usually described in terms of teaching, research/scholarship, and service, and within health science fields, clinical practice expectations. Most academic appointments, regardless of employment at public or private universities, include these components to varying degrees as faculty members' primary responsibilities; successful promotion and/or tenure commonly requires faculty members to excel in one or more of these areas. Organizational citizenship behaviors are not typically articulated in terms of a faculty member's responsibilities, unless they are described in terms of service. Faculty members' behavior when executing their responsibilities may or may not be included in the determination of their success, but could have a significant impact on colleagues, students, and the culture of their department, school/college, and institution.

\section{Definition of Pharmacy Faculty Citizenship}

One of the challenges in defining faculty citizenship for the Academy is how it relates to service expectations. This appears to be due in part to the difficulty in higher education when differentiating faculty service activities from citizenship. ${ }^{12}$ Unlike service, there is a considerable body of literature about activities that are easier to define and measure in higher education such as teaching and research. ${ }^{12-14}$ Neumann and Terosky define institutional service as [faculty member] contributions that support a campus's "mission, operations, and cultural life." 15 There are numerous examples where faculty citizenship is described primarily in terms of service, but also include a subtle "quality" or behavioral component. These examples range from promotion/tenure and merit raise criteria, to college and university citizenship awards. ${ }^{16-20}$ It seems then that some descriptions of citizenship contain elements of service and interpersonal behavior.

Based on relevant literature and author discussions, the authors offer the following definition of "Faculty Citizenship" for the Academy: Faculty citizenship is a pattern of behaviors by pharmacy faculty members that promotes the welfare of the school or college of pharmacy, and as a consequence, the larger university structure. It consists of two primary components: engagement and collegiality.

This definition encompasses the idea that anyone can have a bad day here and there; therefore, the focus should be on a pattern of behavior. It also emphasizes the impact of individual behaviors regarding the welfare of the organization. Lastly, this definition delineates two primary observable behavioral components of engagement and collegiality. Engagement is defined as positive contributions by a pharmacy faculty member in assigned activities and participation in additional opportunities toward the development and advancement of their department, school, university, discipline, profession, and/or practice site. Collegiality is defined as interpersonal behaviors that promote a positive and productive work environment and culture that ultimately benefit other faculty, students, and constituents, as well as the department, school, university, discipline, profession, and/or practice site in which the faculty member is engaged.

A key part of the definition is that it does not link citizenship to any specific faculty role. This means a school could establish citizenship expectations for any or all parts of the school's mission to provide an opportunity to recognize and reward individuals who go beyond the basic requirements. Perhaps the greatest contribution of the definition is a distinction of the service aspects (engagement) and behavioral aspects (collegiality) of faculty citizenship. Faculty citizens exhibit behaviors that demonstrate engagement and collegiality with the goal of optimizing relationships, responsibilities and opportunities.

\section{Importance of Organizational and Faculty Citizen- ship}

Although most of the OCB literature has focused on antecedents to OCBs, such as job satisfaction and trust, a growing body of research indicates a positive relationship between organizational citizenship behaviors and both individual and organizational outcomes. A meta-analysis conducted by Podsakoff and colleagues provides a thoughtful and comprehensive review of OCB consequences; its findings include increased efficiency and reduced turnover in business organizations. ${ }^{9}$ Other studies have determined OCB may contribute to success by 


\section{American Journal of Pharmaceutical Education 2019; 83 (4) Article 7378.}

enhancing coworker or managerial productivity, freeing resources for productive purposes, reducing the need to allocate resources to maintenance, and serving as a means of coordinating activities. ${ }^{21-23}$ Additional contributions include enhancing the organization's ability to attract and retain skilled employees and enhancing the stability of the organization's performance and its ability to adapt to environmental changes. ${ }^{21-23}$ Interestingly, the concept of citizenship fatigue has been studied as a phenomenon that may occur when employees demonstrate high levels of OCB in an organization with low support for OCB. ${ }^{24}$ Overall, however, positive organizational citizenship behaviors were associated with positive outcomes from an employer perspective.

Reasons for considering faculty citizenship in the Academy are similar to those found in any organization. Although lacking a robust empirical foundation, its importance to the Academy and to the development of student pharmacists can still be asserted on multiple levels. At the profession level, elements of collegiality and engagement are at the core of both the "Pharmacist Code of Ethics" and the "Oath of the Pharmacist." Faculty modeling of collegiality and engagement in the educational process is important, therefore, in the development of future pharmacists. Schools and colleges of pharmacy across the United States, like many organizations, are facing the challenge of meeting and advancing organizational goals in an increasingly efficient or "lean" manner. Faculty citizenship behaviors likely facilitate meeting this challenge.

At the program level, positive faculty citizenship likely also plays a role in students' satisfaction with their education, which might influence their future donations back to and engagement with the school as alumni. In addition to literature supporting the relationship between OCB and customer satisfaction, Gallup research notes the importance of student mentoring, a potential faculty citizenship activity, in students' post-graduation wellbeing. ${ }^{25}$ It also stands to reason that positive mentoring during students' academic careers leads to positive student outcomes. Table 1 summarizes ways in which various stakeholders might find faculty citizenship to be an important behavior.

\section{Incorporating Faculty Citizenship into Faculty Evaluation}

There seem to be few published examples in the Academy, as well as higher education, where citizenship or collegiality expectations are clearly defined and measured. One study used a cross-sectional self-administered survey to examine the perception of pharmacy faculty toward OCB and organizational culture. The results identified a reliable matrix to assess citizenship behavior across academic pharmacy institutions. ${ }^{2}$ Related to collegiality, the American Association of University Professors has a statement about its evaluation. ${ }^{26}$ While the organization recognizes the importance of collegiality in the life of a faculty member and its importance to an institution's functioning, it discourages the evaluation of collegiality as a separate measure in the promotion and tenure process. Instead, it notes that collegiality should be integrated and expressed in the major facets of faculty life: teaching, research and service.

Other practical considerations in using faculty citizenship in the evaluation process are determining who measures it and how it should be documented. Sources of documentation may include students, peers, selfevaluation, and a department chair's evaluation of

Table 1. Importance of Faculty Citizenship to Schools and Colleges of Pharmacy and Their Stakeholders

\begin{tabular}{ll}
\hline Colleges and Schools & Facilitates accomplishing and advancing the mission of the organization \\
& Models the service aspect of the pharmacy profession \\
& Enhances the image of the college or school \\
& Positively impacts recruitment and retention of faculty and staff \\
& Promotes faculty-student collegiality, mentoring and relationship development \\
& Models professional service expectations post-graduation \\
Enrolled Students & Promotes deeper learning and enhanced practice experiences \\
Promotes student recruitment to colleges and schools & Influences a student's decision to pursue pharmacy through modeling of the overarching \\
Potential Students & values and virtues of a pharmacist \\
Faculty & $\begin{array}{l}\text { Influences productivity, organizational commitment, and job satisfaction of current faculty and staff } \\
\text { Encourages sharing of new ideas, suggestions, opinions } \\
\text { Influences promotion and tenure decisions, even if not explicitly evaluated } \\
\text { influences the nature and extent of faculty extra-role behaviors, to the extent that FC is } \\
\text { perceived to be valuable to the institution } \\
\text { Models expectations of intra- and inter- professional collegiality }\end{array}$ \\
Alumni &
\end{tabular}




\section{American Journal of Pharmaceutical Education 2019; 83 (4) Article 7378.}

citizenship behaviors. The documentation itself may consist of results of a standardized proprietary questionnaire such as the Atlas Self-Assessment Matrix (S-AM) or Collegiality Assessment Matrix (CAM), ${ }^{27}$ a locally created checklist, rubric, or form for recording information, or letters from others describing citizenship behaviors. If documentation of citizenship proves difficult or too onerous, documenting a consistent lack of it may be another, albeit negative, approach. Once defined and operationalized, the decision to incorporate faculty citizenship expectations into faculty performance evaluations should also determine whether faculty citizenship will be considered across all or part of the school's mission, and how, where and when it would be used, such as for all annual performance reviews or just for high stakes reviews such as promotion or tenure.

In identifying patterns of citizenship behavior, one could consider the frequency of the observed behavior. For example, it could be determined whether a colleague rarely/sometimes/usually/always is a contributing member of a committee, volunteers to help with a project or task when help is needed, or provides informal consultations or advice to colleagues as needed (eg, hallway consultations). Colleagues who are usually or always exhibiting a behavior have clearly established a pattern of behavior. Allowances should be made for the different ways faculty members can demonstrate their citizenship as well as for those occasional "bad days" that can happen to anyone. Likewise, respectful disagreements with colleagues are not considered poor citizenship when they are conducted in a constructive manner, promote a healthy dialogue, and do not detract from the welfare of the school or institution.

Of the two primary components of faculty citizenship, collegiality is probably the most difficult to measure. Again, the focus should be on collegial behavior over time with a focus on those behaviors that promote the institution and profession, contribute to a positive and productive work environment, and create positive effects through assigned activities and pursuit of additional opportunities to serve constituents. Easterling suggests some collegiality behaviors such as verbal and nonverbal signs of respect, civility in interactions with each other, self-motivated collaboration and cooperation on departmental, teaching, and scholarly activities, and intentional, professional interactions between peers. ${ }^{28}$

Institutions interested in measuring faculty citizenship should also consider that related expectations for any faculty member can vary greatly based upon the role of the individual within the pharmacy program, the relationship of the expectee to the expectant (eg, the department chair's expectation of a faculty member versus a peer's expectation of that same faculty member), and the culture of the institution. The definition of faculty citizenship used in this commentary can be described and measured as a set of expected behaviors so that a determination can be made as to whether individual faculty members meet, exceed, or do not meet these expectations. These determinations could be used for professional development, annual evaluations, or even recognition and awards for high levels of faculty citizenship.

\section{Ongoing Considerations of Faculty Citizenship}

Discussions in the Academy have revealed an interest in the concept of faculty citizenship but also potential negative consequences of such evaluations as real or perceived infringements on academic freedom, judgments on personality, and unnecessarily changing/complicating the nature of promotion and tenure criteria. These concerns exemplify the distinction between citizenship behaviors in higher education as compared to organizations in general. Moreover, these concerns certainly deserve continued conversation. Generally, however, colleagues have expressed positive interest in the concept and its use.

From a foundation of business and psychology evidence, Dr. Nance Lucas, executive director of the Center for the Advancement of Well-Being at George Mason University, leads professional development workshops on wellbeing as it applies to leadership, teamwork and organizational culture. This evidence seems directly applicable to the concept and practice of faculty citizenship, especially when discussing business concepts of engagement versus disengagement. The literature supports the importance of behavior in the workplace and its impact on an organization's culture, productivity and profitability. Dr. Lucas has shared that positive and engaged employees are more productive and that economic loss because of disengaged employees could be upward of $25 \%$ of a company's value. ${ }^{3}$ Related to this programming, there was a session at the 2018 AACP Annual Meeting that focused on evidence-based approaches to fostering collegiality and civility to enhance organizational culture. Participants used a Collegiality and Responsiveness Self-Assessment to become familiar with relevant behaviors. They also discussed faculty behavior case studies from the perspective of colleagues and administrators and debated the merits of assessing faculty behavior in the promotion and tenure process. ${ }^{4}$

\section{CONCLUSION}

Based on the evidence, a relationship between faculty or employee behavior and organizational culture exists. Faculty members showing high levels of citizenship 


\section{American Journal of Pharmaceutical Education 2019; 83 (4) Article 7378.}

behaviors can be considered engaged employees. Conceivably, engaged faculty contribute to greater productivity and employee satisfaction in our schools and universities. Faculty citizenship is likely to have significant impact, both positive and negative, in our schools and colleges of pharmacy regardless of whether it is or is not actually measured. By providing a definition with two primary components of faculty citizenship, this commentary provides additional dialogue to stimulate further discussion and research on faculty citizenship behaviors and how they impact the Academy.

\section{ACKNOWLEDGMENTS}

The committee would like to thank Steve Scott, PharmD, for his leadership and vision to formally explore this concept through the AACP Council of Faculties committee structure, and Cecilia Plaza, PharmD, PhD, for her staff support of the committee's work.

\section{REFERENCES}

1. Desselle SP, Semsick GL. Organizational citizenship behaviors in academic pharmacy. Am J Pharm Educ. 2016;80(10):Article 168.

2. Desselle S, Raja L, Brienna A, Lui J. Perceptions of organizational culture and organizational citizenship by faculty in U.S. colleges and schools of pharmacy. Curr Pharm Teach Learn. 2018;10(4):401-412.

3. Lucas N. Leading to wellbeing. Workshop at American Association of Colleges of Pharmacy Interim Meeting; February 2016; Tampa, FL.

4. Stein S, Van Amburgh J. Drawing castles in the sand: Fostering collegiality and civility. Special session at American Association of Colleges of Pharmacy Annual Meeting; July 2018; Boston, MA. 5. Accreditation Council for Pharmacy Education. Accreditation standards and key elements for the professional program in pharmacy leading to the Doctor of Pharmacy degree. (Standards 2016.) https:// www.acpe-accredit.org/pdf/Standards2016FINAL.pdf. Published February 2015. Accessed September 14, 2018.

6. DiVall M, Trujillo J. AACP minutes, council of faculties business meeting, July 13, 2015; National Harbor, MD. Am J Pharm Educ. 2015;79(8):Article S11.

7. Moorman RH. Relationship between organizational justice and organizational citizenship behaviors: do fairness perceptions influence employee citizenship? J App Psych. 1991;76:845-855.

8. Batemen TS, Organ DW. Job satisfaction and the good soldier: the relationship between affect and employee "citizenship." Acad Mgmt J. 1983;26:587-595.

9. Podsakoff NP, Whiting SW, Podsakoff PM, Blume BD. Individual- and organizational-level consequences of organizational citizenship behaviors: A meta-analysis. J App Psych.

2009;94(1):122-141.

10. Organ DW. Organizational Citizenship Behavior: The Good Soldier Syndrome. Lexington, MA: Lexington Books; 1988.

11. Lawrence J, Ott M, Bell A. Faculty organizational commitment and citizenship. Res High Educ. 2012;53:325-352.
12. Edgerton R. The re-examination of faculty priorities. Change. 1993;25(4):16.

13. Filetti JS. Assessing service in faculty reviews: Mentoring faculty and developing transparency. Mentoring \& Tutoring: Partnering in Learning. 2009;17(4):343-352.

14. Neumann A, Terosky A. To give and to receive: recently tenured professors' experiences of service in major research universities.

$J$ High Educ. 2007;78(3):282-310.

15. Neumann A, Terosky A. To give and to receive: recently tenured professors' experiences of service in major research universities.

J High Educ. 2007;78(3):283.

16. University of New Mexico College of Pharmacy, Department of Pharmacy Practice and Administrative Sciences Promotion and Tenure Criteria. Revised July 2013.

17. Virginia State University. Criteria for the Award of Tenure to Collegiate/Instructional Faculty, SU 2.5.2. 2013 Ed. http://vsu.edu/ files/docs/faculty-staff/faculty-handbook.pdf. Accessed September 14, 2018 .

18. Boston University College of Arts and Sciences. Faculty Merit Exercises. Boston, MA. https://www.bu.edu/cas/files/2015/02/MeritMemo-Part-One-2018-1.pdf. Accessed December 4, 2018.

19. Kent State University Department of Physics. Physics Faculty Handbook. https://www.kent.edu/physics-faculty-handbook/ university-citizenship. Accessed December 4, 2018.

20. University of Missouri System. Presidential Faculty Award for University Citizenship. https:/www.umsystem.edu/media/ Presidents_Award_-_University_Citizenship.pdf. Accessed December 4, 2018.

21. Podsakoff PM, MacKenzie SB, Moorman RH, Fetter R. Transformational leader behaviors and their effects on followers' trust in leader, satisfaction and organizational citizenship behaviors. Lead Qrtr. 1990;1:115.

22. Podsakoff PM, MacKenzie SB, Paine JB, Bachrach DG. Organizational citizenship behaviors: a critical review of the theoretical and empirical literature and suggestions for future research. J Mgmt. (2000);26:513-563.

23. Podsakoff PM, MacKenzie SB. Organizational citizenship behaviors and sales unit effectiveness. J Mkt Res. 1994;3:351-363. 24. Bolino MC, Hsiung HH, Harvey J, LePine JA. Well, I'm tired of tryin'! Organizational citizenship behavior and citizenship fatigue. $J$ App Psych. 2015;100(1):56-74.

25. Busteed B. The blown opportunity. Inside Higher Ed.

Washington, DC. September 25, 2014. https://

www.insidehighered.com/views/2014/09/25/essay-about-

importance-mentors-college-students. Accessed December 4, 2018.

26. American Association of University Professors. Reports and publications, on collegiality as a criterion for faculty evaluation. https://www.aaup.org/report/collegiality-criterion-facultyevaluation. Published 1999. Revised 2016. Accessed December 4, 2018.

27. Cipriano RE, Buller JL. Rating faculty collegiality. Change. 2012;44(2):45-48. http://www.atlasleadership.com/forms-andinstruments.html. Accessed December 4, 2018.

28. Easterling WV. Collegiality: A singular concept? Indiana University-Purdue University Indianapolis (IUPUI) ScholarWorks Repository. 2011. https://scholarworks.iupui.edu/handle/1805/2539. Accessed December 4, 2018. 